\title{
Surgical Management of a Case of Splenic Necrosis at Point G Chu in Bamako
}

\author{
Moussa Sissoko*, Mahamadou Coulibaly, Sékou Koumaré, Oumar Sacko, Sidiki Keïta, \\ Soumaila Keita, Siaka Diallo, Lamine Soumaré, Adama F. Traoré, Adama Koïta, Moussa Camara, \\ Aboubacar Camara, Hammadoun Dicko, Djibril Sangaré, Zimogo Z. Sanogo
}

General Surgery “A” Department, Hospital Point-G., Bamako, Mali

Email: ^moussasissoko208@gmail.com

How to cite this paper: Sissoko, M., Coulibaly, M., Koumaré, S., Sacko, O., Keïta, S., Keita, S., Diallo, S., Soumaré, L., Traoré, A.F., Koïta, A., Camara, M., Camara, A., Dicko, H., Sangaré, D. and Sanogo, Z.Z. (2021) Surgical Management of a Case of Splenic Necrosis at Point G Chu in Bamako. Surgical Science, 12, 103-106. https://doi.org/10.4236/ss.2021.124012

Received: November 17, 2020

Accepted: April 11, 2021

Published: April 14, 2021

Copyright $\odot 2021$ by author(s) and Scientific Research Publishing Inc. This work is licensed under the Creative Commons Attribution International License (CC BY 4.0).

http://creativecommons.org/licenses/by/4.0/

\section{(c) (i) Open Access}

\begin{abstract}
Splenic infarction is a rare condition $(1 / 500,000$ and $1 / 100,000)$ but potentially fatal. The prognosis depends on the diagnostic delay and above all on the speed of treatment. It usually occurs in a particular area such as myeloproliferative syndrome, sickle cell anemia, thalassemia etc. The objective of this work was to report a clinical case of necrosis of the spleen.
\end{abstract}

\section{Keywords}

Splenic Necrosis, “A” Surgery, CHU Point G

\section{Introduction}

Splenic infarction is a little known condition with a prevalence of $1 / 500,000$ and $1 / 100,000$ cases, but potentially fatal. This mortality is mainly linked to diagnostic and therapeutic delay, as well as to the risks related to the site and the seriousness of the underlying pathology [1].

It usually occurs in an abnormally enlarged spleen, either as a result of a myeloproliferative syndrome or by vascular occlusion as in sickle cell anemia, thalassemia [2].

The repetition of these infarcts can considerably decrease the functional capacity of the spleen. It causes alteration in its roles of filtering and removing blood cells and storing platelets, the risk of serious infection from secondary immune deficiency.

The diagnosis is suggested in cases of hemorrhagic shock associated with abdominal pain in the absence of any trauma. This diagnosis is based on the results of an abdominal ultrasound and CT scan.

Splenic infarction may be clinically silent or may manifest as severe pain in 
the left hypochondrium [3].

The treatment is essentially surgical (splenectomy).

The objective of this work was to report a clinical case of spleen necrosis in the " $\mathrm{A}$ " surgical department at the Point G University Hospital.

\section{Clinical Observation}

We report a clinical case of spleen necrosis. This was a 28 -year-old patient, a trader by profession, with known sickle cell disease with SC without any particular surgical history. He was referred to us by his doctor brother for abdominal pain.

On clinical examination we found conjunctival-palmoplantar pallor, abdominal pain evolving for 3 days, located in the left flank, of strong intensity, diffuse irradiation, without calming factors or triggering factors associated with an unquantified fever. Palpation found a mass extending from the left hypochondrium to the left iliac fossa, painful, fixed, firm, measuring $15 \mathrm{~cm}$ transverse axis and $25 \mathrm{~cm}$ cranio-caudal axis. The examination of the other organs was unremarkable.

The result of the abdominopelvic ultrasound was in favor of a heterogeneous spleen with irregular contours, surrounded by a large echogenic fluid collection of $175 \times 166 \mathrm{~mm}$ and a sub-capsular hemorrhage with splenic necrosis.

The appearance suggestive of a spontaneous rupture of the spleen with probably involvement of the splenic artery and homogeneous hepatomegaly without focal lesion was found on CT.

An emergency preoperative workup including $\mathrm{CBC}$, rhesus group, serum creatinine, blood sugar was performed.

Under general anesthesia with orotracheal intubation, intraoperatively we discovered a large mass of fluid content whose puncture brought back pus chocolate, necrosis of the spleen with a splenic parenchyma completely detached from its vessels. The surgical procedure performed was manual removal of the splenic parenchyma, ligation of the splenic vessels in the rear omentum cavity, resection of the capsule, placement of a tubular drain in the splenic compartment.

The culture of the sample fluid was sterile. The histology of the surgical specimen did not find any tumor. The pneumo 23 vaccine was administered to the patient.

In the immediate postoperative follow-up, the patient presented with a picture of abdominal distension on D5. The ultrasound showed a large peritoneal effusion in favor of ascites. The evacuating puncture emptied $500 \mathrm{ml}$ of citrus yellow liquid. Discharge was authorized on D15 with a request for consultation at the sickle cell research and control center (CRLD).

\section{Discussion}

Non-traumatic rupture of the spleen (spontaneous) is a rare but classic feature of 
splenic-tropic disease. In the literature, the etiology of splenic infarction is thrombosis of the vein and or splenic artery following infection either with $\mathrm{N}$. meningitidis, EBV, HIV and or acute leukemia, lymphoma, to a chronic myeloproliferative syndrome, to vascular tumors, to hemopathies and the taking of certain drugs such as estrogen-progestogens. In the work of Philippe $\mathrm{C}$ et al., the splenic infarction was linked to a thrombosis of the splenic vein [4].

Sickle cell disease with probably thrombosis of the splenic vein was found as an etiological factor in our patient. In the literature, pathologies such as sickle cell anemia are the second cause of splenic infarction and affect patients under 40 years of age [5].

The origin of endemic malaria should be a reason to seek infection with plasmodium vivax which is one of the etiologies

SI is symptomatic in $60 \%$ to $100 \%$ [6], inaugural abdominal pain has been reported in the literature. These are diffuse or localized pain in the left hypochondrium, pelvic pain, fever and/or splenomegaly [7] [8].

Kehrs sign is less found [9]. It is a left scapular irradiation pain reflecting diaphragmatic irritation associated with peritoneal effusion. Abdominal pain syndrome sets in a few days before the rupture. This observation was made in our case, 72 hours before admission. The rupture is rarely indicative of the pathology, it most often occurs in a known area [10].

Splenic infarction alone is not an indication for surgery. Treatment of splenic infarction is symptomatic. Usually, healing occurs within one to two weeks. Complications are noted in about $20 \%$ of cases, most often in the context of infarction secondary to vascular occlusion. It may be a ruptured spleen with subcapsular hemorrhage or hemoperitoneum, a splenic abscess or pseudocyst formation which are the indications for surgery [5]. The histology of the surgical specimen does not find any tumor cells that were palpable on the surgical specimen as shown in Figure 1. This observation was made in our study.

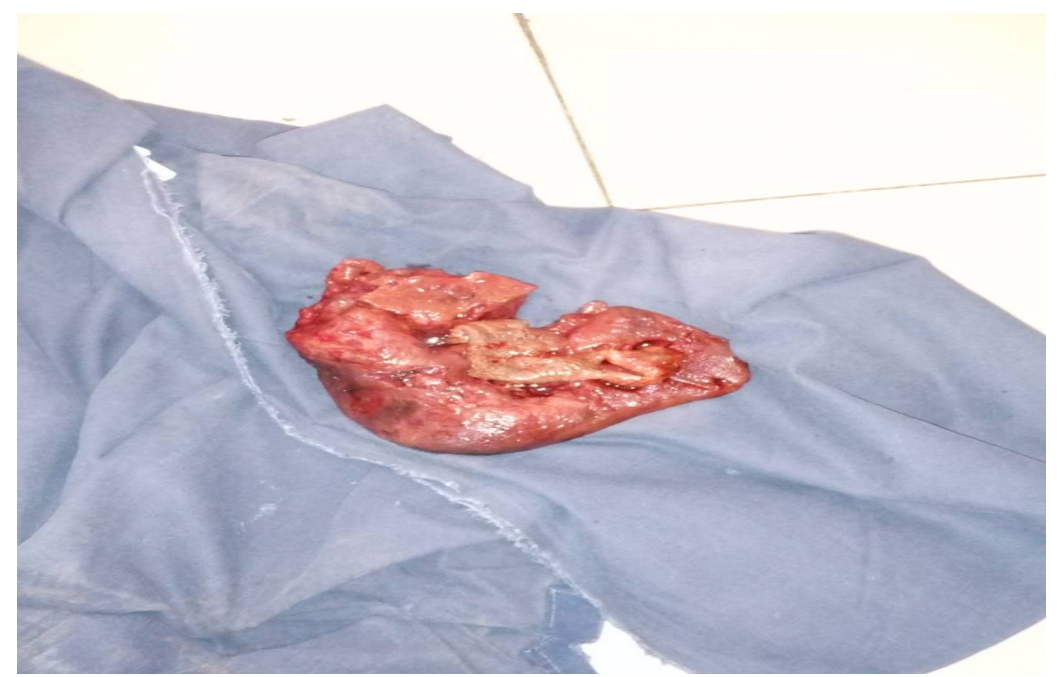

Figure 1. Appearance of the splenic parenchyma postoperatively. Source: Department of surgery A of the CHU of POINT G. 
The prognosis for splenic infarction depends on the underlying pathology.

\section{Conclusion}

Splenic infarcts are of a wide variety of conditions, sometimes serious, and should always be investigated. Complications and prognosis appear to be related to the underlying pathology.

\section{Conflicts of Interest}

There is no conflict of interest. The patients gave their consent for the realization of this article.

\section{References}

[1] Honsel, V. and Ruivarfd, M. (2017) Embolisation du tronc de l'artère splénique. Revue de Médecine Interne, 2, 98. https://doi.org/10.1016/j.revmed.2017.10.401

[2] Ismail, S., Laurent, H., Christophe, B., Jean-Paul, B. and José, S. (2003) SPLENIC Necrosis after Percutaneous Celiac Plexus Block Guided by Ultrasonography. Gastroentérologie Clinique et Biologique, 3, 339-340.

[3] Thony, F., Rodière, M., Frandon, J., Vendrell, A., Jankowski, A., Ghelfi, J., Sengel, C., Arvieux, C., Bouzat, P. and Ferretti, G. (2015) Polytraumatismes et Syndromes Hémorragiques. Journal de Radiologie diagnostique et interventionnelle, 3, 264-272. https://doi.org/10.1016/j.jradio.2015.06.007

[4] Corne, P., Borie, F., Gallix, B., et al. (2004) Infarctus splénique révélant une méningococcémie. Gastroentérologie Clinique et Biologique, 28, 197-198. https://doi.org/10.1016/S0399-8320(04)94881-6

[5] Kassem, H., et al. (2017) Primo-infection à cytomégalovirus: Une cause infectieuse d'infarctus splénique. La Revue de Médecine Interne, 38, 555-557.

https://doi.org/10.1016/j.revmed.2016.12.017

[6] El Aoud, S., Morin, C., Dagnet, S., et al. (2020) Infarctus splénique révélant un accès palustre à Plasmodium vivax. Médecine et Maladies Infectieuses, 50, 746-747. https://doi.org/10.1016/j.medmal.2020.04.012

[7] Demeter, A. and Gelfand, M.S. (1999) Abdominal Pain and Fever-An Unusual Presentation of Meningococcemia. Clinical Infectious Diseases, 28, 1327. https://doi.org/10.1086/517786

[8] Schmid, M.L. (1998) Acute Abdomen as an Atypical Presentation of Meningococcal Septicaemia. Scandinavian Journal of Infectious Diseases, 30, 629-630. https://doi.org/10.1080/00365549850161296

[9] Haaga, J.R., Kori, S.H., Eastwood, D.W. and Borkowski, G.P. (1984) Improved Technique for CT-Guided Celiac Ganglia Block. American Journal of Roentgenology, 142, 1201-1204. https://doi.org/10.2214/ajr.142.6.1201

[10] Hamidou, D., Léra, G.A., Seynabou, F., Nfaly, B., Ibrahima, K., Mohamadou, L.G., Mouhamed, H.T. and El Hadj, N. (2016) Torsion chronique d'une rate baladeuse chez un adolescent à propos d'un cas. The Pan African Medical Journal, 1, 1-6. 